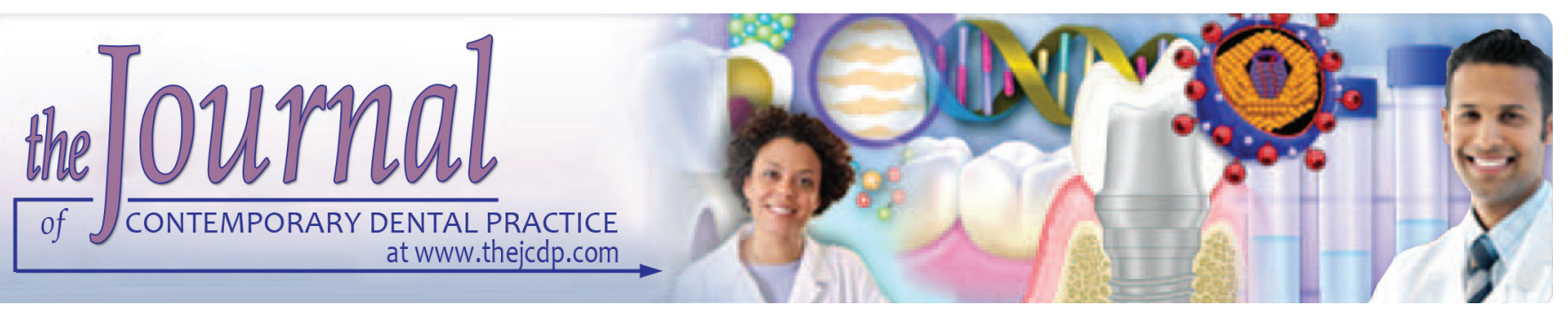

\title{
Evaluation of Apical Dimension, Canal Taper and Maintenance of Root Canal Morphology Using XP-endo Shaper
}

${ }^{1}$ Afif Tabbara, ${ }^{1}$ Dan Grigorescu, ${ }^{1,2}$ Mohammed A Yassin, ${ }^{1}$ Inge Fristad

\section{ABSTRACT}

Aim: To evaluate the shaping ability of the XP-endo shaper file system in maxillary molars, representing root canals with variation in morphology.

Materials and methods: Twenty maxillary molars were instrumented according to recommended protocols. Pre- and postoperative microcomputed tomography (CT) scans were performed and the root canals classified according to canal type and curvature. The volume change, number of strokes needed to prepare the canals and the size of the 0.04-tapered gutta-percha cone that was adapted in the canal were recorded.

Results: XP-endo shaper created a significant change in volume after instrumentation in all the canals, with the biggest change found in the DB canals, followed by the MB1 and the $\mathrm{P}$ canals, both at full length and in the apical $4 \mathrm{~mm}$. The number of strokes needed to achieve working length and final shape did not differ between the various root canals. Although not significant, the number of strokes needed to prepare the root canal increased with severity of the curvature, but the severity of the curvature did not result in increased removal of dentin in the apical $4 \mathrm{~mm}$. It was possible to achieve a final root canal size where a 0.04-tapered gutta-percha cone could be adapted.

Conclusion: The XP-endo shaper was a safe and effective instrument to achieve a root canal preparation of at least size 30 and a 0.04 taper.

Clinical significance: The clinical performance of XP-endo shaper was to some extent dependent on preoperative volume and curvature of the root canal.

Keywords: Endodontics, Microcomputed tomography, Root canal preparation, Three-dimensional shaping.

${ }^{1}$ Department of Clinical Dentistry, University of Bergen, Bergen, Kingdom of Norway

2Department of Fibre and Polymer Technology, KTH Royal Institute of Technology, Stockholm, Kingdom of Sweden

Corresponding Author: Inge Fristad, Department of Clinical Dentistry, University of Bergen, Bergen, Kingdom of Norway, e-mail: inge.fristad@uib.no
How to cite this article: Tabbara A, Grigorescu D, Yassin MA, Fristad I. Evaluation of Apical Dimension, Canal Taper and Maintenance of Root Canal Morphology Using XP-endo Shaper. J Contemp Dent Pract 2019;20(2):136-144.

Source of support: Nil

Conflict of interest: None

\section{INTRODUCTION}

Root canal preparation is performed by mechanical instrumentation and chemical irrigation. ${ }^{1,2}$ A suitable final preparation is needed, usually a tapered shape with sufficient size, to facilitate proper cleaning and filling of the root canal space. ${ }^{3,4}$

Three-dimensional (3D) cleaning, shaping, and obturation of the root canal system have been a desired goal during root canal treatment. The introduction of NiTi rotary files made a major change in endodontics, but after years of intensive development and modification, most of these instruments still share several drawbacks, perhaps the major one being the inability to three-dimensionally clean and shape oval root canals. Present instruments are not able to clean the entire root canal system in a predictable manner. ${ }^{4-7}$ Especially in the apical portion of the root canals, and the cleaning efficiency is limited. 2,8-15

Micro-CT scanning technology has been widely used to evaluate the effect of different instruments within the root canal system. Studies have revealed that a relatively large amount of the surface area within the main canal remains un-instrumented, irrespective of instruments used. ${ }^{16-19}$ Untouched areas have the potential to harbor remnants of bacterial biofilm and pulp tissue. ${ }^{16,20}$ Failure to adequately clean the root canal space may thus result in treatment failure or delayed healing. ${ }^{21-24}$ Also, earlier studies have indicated that differences in canal anatomy between palatal (P), mesiobuccal (MB), and distobuccal (DB) canals play a significant role in the shaping outcome. ${ }^{25}$ More ribbon-shaped or flat canals, 
such as the MB canal, would have more unprepared canal areas. Moreover, narrow and more curved MB canals have greater canal transportation than $\mathrm{P}$ canals. ${ }^{26}$ Studies based on Micro-CT provide accurate data on the preparation effect for different hand and rotary instruments in maxillary molars. $6,13,25-27$

Along with the detailed three-dimensional information obtained by micro-CT, renewed interests in instruments that can achieve better cleaning, particularly in irregular root canals with complex anatomy, have emerged. Measures aiming at achieving a better threedimensional cleaning and shaping include ultrasonic instrumentation and use of endodontic files that can adapt to the shape of the root canal. The self-adjusting file (SAF) and TRUShape files belong to these instruments. Numerous studies performed with the SAF have revealed its shaping ability in complex root canal anatomy, ${ }^{28,29}$ with less deviation and preservation of the original root canal anatomy. ${ }^{30,31}$ In addition, the TRUShape file has proven effective in a variety of canals with different geometry, ${ }^{32,33}$ with minimal canal transport. ${ }^{17}$ On the contrary, a study showed that both files have their limitations and behave similarly to the rotary and reciprocating instruments. ${ }^{34}$

Recently, a new endodontic file, the XP-endo Shaper from FKG, was introduced for root canal preparation. The company claims that the shape of the instrument facilitates optimal dentin removal along the perimeter of variable canals, providing a better three-dimensional cleaning of the root canal space. The literature on characteristics and shaping abilities of XP-endo Shaper is limited. ${ }^{35-40}$ The XP-endo Shaper is an innovative broad-spectrum shaping instrument made from the MaxWire alloy (Brasseler, Savannah, GA). The XP-endo Shaper is a "1-file shaper" claimed to expand at body temperature within canals, and contract to adapt itself to the canal morphology. The instrument has a size/ taper of 30/0.01, which, according to the manufacturer, makes it more flexible and resistant to cyclic fatigue. The $\mathrm{XP}$-endo Shaper can reach a final canal preparation of a minimum size/taper of 30/0.04. Its booster tip enables the instrument to start shaping a canal with an initial diameter smaller than the instrument.

The aim of this study was to evaluate the canal shaping properties of the XP-endo Shaper in maxillary molars, with focus on dentin removal ability and final root canal shape.

\section{MATERIALS AND METHODS}

\section{Tooth Selection}

This ex vivo study was conducted at the Department of Clinical Dentistry, University of Bergen, Norway.
Twenty human maxillary molar teeth with intact un-instrumented roots, scheduled for routine extraction of unknown reasons in private and public clinics in Bergen, Norway, were used in this study. Teeth were stored in $1 \%$ benzalkonium chloride until use. All teeth were pre- and postoperatively scanned with a Sky Scan 1172 micro-CT scanner (Bruker micro-CT, Belgium). Root canal curvature was measured on $\mathrm{CBCT}$ preoperative radiographs to ensure the largest value for each root. The root canal curvature was categorized as straight (angle <5), moderate (angle between $\geq 5$ and <20) and severe $(\geq 20)$ according to Schneider. ${ }^{41}$ When applicable, Cunningham \& Senia's method for S-shaped canals was used. ${ }^{42}$ The curvatures were defined as straight (ST), moderate curvature (MC), severe curvature (SC) according to Schneider, and S-form (SF) characterized as double curvature.

\section{Root Canal Preparation}

All teeth were accessed through the crown using a high-speed diamond bur. An ISO 10/0.02 K-file was used to explore the root canal until the instrument tip was visible at the apical foramen (patency length), using a dental microscope. The working length (WL) was set $0.5 \mathrm{~mm}$ shorter than patency length in all root canals. An intraoral radiograph confirmed the WL. A glide path was established with hand instruments to ISO 15/0.02. Each tooth was then immersed up to the cementoenamel junction in a warm water bath $\left(37^{\circ} \mathrm{C}\right)$ during instrumentation. The temperature was kept constant using a heat-controlled thermostat (Thermo Electron, Karlsruhe, Germany). Dakin's solution, kept at $37^{\circ} \mathrm{C}$ throughout the experiment, was used as irrigation. Calasept irrigation needles, 31G, $0.28 \times 25$ (Directa Inc, Newton, USA) was used during the irrigation procedure. Instrumentation was performed by two calibrated operators.

\section{XP-endo Shaper Instrumentation Technique}

The XP-endo Shaper (FKG, Switzerland) was operated at $800 \mathrm{rpm}$ and $1 \mathrm{Nm}$ torque. The pulp chamber was filled with preheated irrigation. The file was used according to the manufacturer's instruction starting with the widest canal, meaning $\mathrm{P}$ canal, followed by the DB, MB1 and MB2 canal. The file was inserted in the canal and 3 to 5 strokes (in-and-out motion) were applied until the file reached $0.5 \mathrm{~mm}$ short of the WL (adjusted WL) as recommended by the manufacturer. In case the file failed to reach the adjusted WL within 3-5 strokes, the canals were again irrigated, glide path using an ISO 15/0.02 K-file was confirmed, before the procedure was repeated. Once the file reached the adjusted WL, 10 up-and-down 
movements were made. The preparation was then checked with a 0.04 tapered gutta-percha cone(Roeko ${ }^{\circledR}$, Coltene/Whaledent, Altstätten, Switzerland), choosing the size of the gutta-percha that reached working length and had a tug back effect. The tip of the gutta-percha cones was standardized using a gutta-percha-point gauge (Dentsply, Maillefer, Ballaigues, Switzerland). If the guttapercha cone 30/0.04 did not adapt to the instrumented root canal at working length, another 10 up-and-down movements were made with the file to the adjusted WL. The preparation was again checked, and the size of the 0.04 gutta-percha cone that adapted to the instrumented root canal was noted. The number of strokes needed to reach the $\mathrm{WL}$, strokes needed for final instrumentation of the root canals and the matching gutta-percha cone for each canal was recorded.

\section{Scanning and Micro-CT Analysis}

All teeth were examined by periapical radiographs and with the SkyScan 1172 micro-CT scanner parameters set at $70 \mathrm{kV}$ and $140 \mu \mathrm{A}$ with an $\mathrm{Al} / \mathrm{Cu}$ filter and camera pixel size of $9 \mu \mathrm{m}$. Teeth were scanned with a $360^{\circ}$ vertical axis rotation, with a single rotation step of $0.6^{\circ}$. To scans, one before and one after instrumentation were performed per tooth. A flat field correction was taken prior to scanning to correct for variations in the pixel sensitivity of the camera.

All scans were 3D reconstructed using NRecon software (Bruker micro-CT, Kontich, Belgium) with a smoothing kernel equal to 2 (Gaussian), beam hardening correction of $51 \%$ and ring artifact correction of 7 . The scanning and reconstruction parameters were kept constant for the pre- and post-instrumentation scans and each 3D image was superimposed manually, using the 3D image registration function in DataViewer software (Bruker micro-CT, Kontich, Belgium). A fixed task list for each scan was used for the image processing operations, binarization and 3D analysis. Table 1 presents the task list used for custom processing.

The region of interest was determined individually for each root canal, using the CTAn software (Bruker

Table 1: Task list used for custom processing

\begin{tabular}{l} 
Task list \\
\hline Threshold global 55-255 \\
Opening 3D space radius 4 \\
Sweep 3D space \\
Region of interest = Copy of image \\
Remove pores 2D space \\
Image = image XOR region of interest \\
Remove white speckles 3D spaces \\
Region of interest = Copy of image \\
3D analysis \\
Create 3D model
\end{tabular}

micro-CT, Kontich, Belgium). The upper limit was set at the cementoenamel junction, whereas the lower limit was selected at the most apical part (apical constriction) of the root canal detected by the CTAn software from the postinstrumentation samples. The upper and lower limit was the same for the pre- and post-instrumentation scans, to obtain identical regions of interest for each individual root canal. Volume measures of the canals, both at full length and the last $4 \mathrm{~mm}$, before and after instrumentation were obtained and used for data interpretation. Root canals with a Vertucci type II configuration were excluded from the study.

The virtual volume of the gutta-percha cone in the last $4 \mathrm{~mm}$ was determined using the formula of a frustum of a right circular cone, where $\mathrm{V}$ is the volume, $\mathrm{h}$ is the height and equal to $4, \mathrm{R}$ is the radius of the lower base corresponding to $\mathrm{D} 4$ and $\mathrm{r}$ is the radius of the upper base corresponding to D0 (tip of the gutta-percha cone).

The formula for the volume of a frustum of a right circular cone:

$$
\mathrm{V}=\frac{1}{3} \mathrm{~h}\left(\mathrm{R}^{2}+\mathrm{Rr}+\mathrm{r}^{2}\right)
$$

The percent volume change was calculated as follows:

$$
\frac{\text { Change (value after }- \text { value before) }}{\text { Value before } \times 100}
$$

All scans were visualized and analyzed by both operators.

\section{Data Analysis}

For studying the effect of XP-endo Shaper on dentine removal, Wilcoxon Test was used. The Wilcoxon Test is designed for use with repeated measures; that is when the subjects are measured on two occasions or under two different conditions.

For the number of strokes needed by the XP-endo Shaper to reach working length and final canal dimension in different root canals and the effect of curvature on dentine cutting efficiency of XP-endo Shaper measured in the apical $4 \mathrm{~mm}$, Kruskal-Wallis test was used. Significance levels of less than 0.05 were considered statistically significant.

\section{RESULTS}

The material consisted of 20 teeth containing a total of 61 root canal systems, including 20 palatal canals $(P)$, 18 distobuccal canals (DB), 11 mesiobuccal one canals (MB1), 3 mesiobuccal two canals (MB2) and 9 merged root canals systems in which either MB1 and DB or the MB1 and MB2 intersect, forming a Vertucci class II.

Three roots were excluded from the analysis due to anatomical defects or problems during the scanning procedure. For accuracy reasons, canals having a Vertucci class II configuration were excluded. Accordingly, the final material consisted of 48 canals of which 19 were 
P, 17 DB, 10 MB1, and 2 MB2, with the P canal having a mean curvature of $28.21 \pm 2.48$, the MB canal $40.90 \pm 3.15$ and the DB canal $26.47 \pm 5.17$.

Thirty-one XP-endo Shaper files were used for the preparation of the teeth. The main reason for using extra files was unwinding, most frequently occurring in MB2 and DB canals having SC and SF curvatures.

\section{Dentine Removal Ability and Cutting Efficiency Of XP-Endo Shaper}

Here the dentine cutting and shaping efficiency of XP-endo Shaper in the root canals before and after instrumentation were evaluated, both at full length and with a special focus on the apical $4 \mathrm{~mm}$. In addition, the difference in volume of the instrumented canals in the apical $4 \mathrm{~mm}$ and the clinically fitted gutta-percha cone after instrumentation were recorded. The results for each canal group and for all canals together are presented in Graph 1.

The results showed a significant change in volume after instrumentation in all the canals at full length (Graph 1A). The volume change was largest in the DB canals, followed by the MB1 and the P canals, meaning that the XP-endo Shaper file worked less in the $\mathrm{P}$ canals than in the DB and MB1 canals. The two MB2 canals studied separately, showed the largest increase in volume at total length, one with an increase of $1248.13 \%$ and the other $261.09 \%$.

The results also showed a significant change in volume after instrumentation with XP-endo Shaper in the apical $4 \mathrm{~mm}$ (Graph 1A), with the DB canal having the largest volume change, followed by the MB1 and the P canals. The two MB2 canals studied separately showed the largest increase in volume in the apical $4 \mathrm{~mm}$, one with an increase of $1149.09 \%$ and the second $67.93 \%$ compared to the preoperative volume.

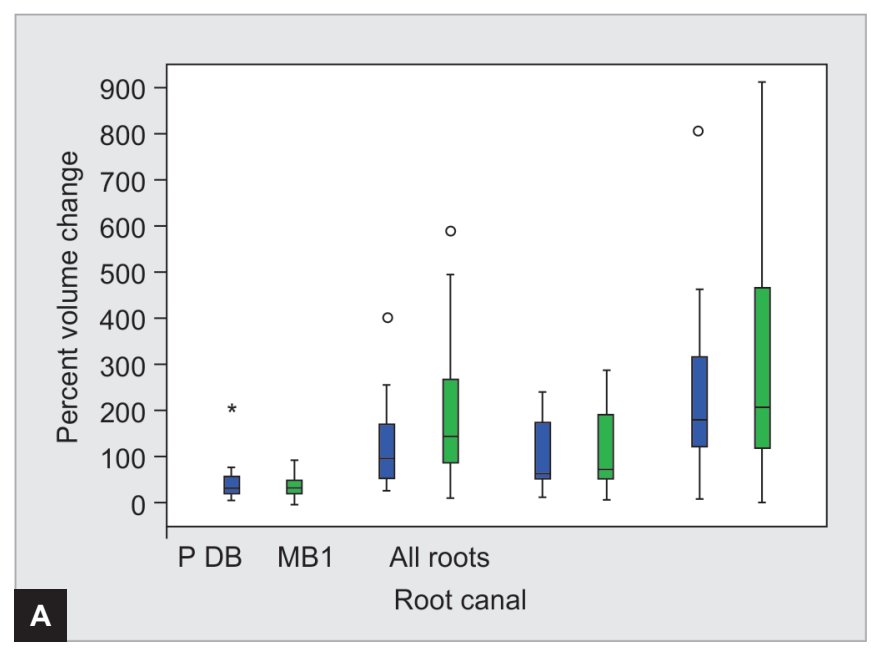

The gutta-percha cone fitted in the apical $4 \mathrm{~mm}$ in the different canals is presented in Table 2. Relative to the canal volume acquired post-instrumentation, a significant difference in the MB1 and P canals was found, but not in the DB canals, meaning that the volume that was not occupied by the gutta-percha cone was significantly bigger in the MB1 and P canals compared to the DB canals as seen in Graph 1B. The result showed that the MB1 canal had the biggest variation in the space created by the XP-endo Shaper and the fitted gutta-percha cone at the apical 4 $\mathrm{mm}$, with a median remaining unoccupied volume of $19.7 \%$. The remaining volume in the $\mathrm{P}$ canals had a lower variation than for the MB1, with a median unoccupied volume of $12.9 \%$. The lowest variation was in the DB canal with a median of $9 \%$. The MB2 canals showed a difference in volume of $8.3 \%$ and $1.3 \%$, which is a relatively minor difference. Three-dimensional reconstructions and micro-CT images are presented in Figures 1 and 2.

\section{Number of Strokes Needed by Xp-Endo Shaper to Reach Working Length and Final Canal Dimension in the Different Root Canals}

The number of strokes gives an idea of the time needed to prepare a root canal system, both for reaching working length and to achieve the final canal shape of the root canal. The number of strokes needed in the different canals is presented in Graph 2.

The results showed no difference in the number of strokes needed to achieve full WL (Graph 2A) and strokes needed for final preparation of the different root canals (Graph 2B).

For the two MB2 canals, 12 and 9 strokes were needed to reach working length, whereas 22 and 19 strokes were used to achieve final shaping of these canals.

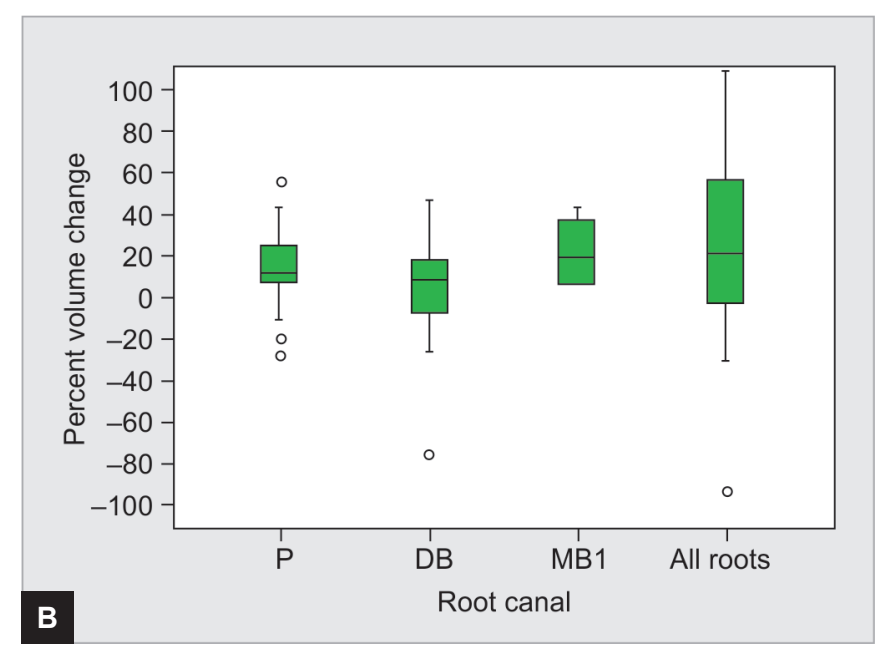

Graphs 1A and B: Volumetric data for the different root canals. (A) Volume change in percent between pre- and post-instrumentation in full-length root canals (blue) and the apical $4 \mathrm{~mm}$ (green) for the different root canals; (B) Volume difference in percent between the instrumented canals and the estimated volume of the clinically fitted gutta-percha cone for the different canals. P, palatal; DB, distobuccal; MB1, mesiobuccal one 


\section{Effect of Root Canal Curvature on Number of Strokes Needed by XP-endo Shaper to Achieve Final Canal Dimension}

Here the effect of root canal curvature on the number of strokes needed by the XP-endo Shaper to achieve the final canal shape was studied. ST and MC curvatures were pooled in one group $(n=10)$ for statistical purposes, while SC $(n=27)$ and SF $(n=11)$ configurations were

Table 2: Variation of gutta-percha cones fitted in different canals

\begin{tabular}{llllll}
\hline Canals & $30 / 0.04$ & $35 / 0.04$ & $40 / 0.04$ & $45 / 0.04$ & $50 / 0.04$ \\
\hline P & 5 & 7 & 5 & 1 & 1 \\
DB & 14 & 3 & 0 & 0 & 0 \\
MB1 & 7 & 3 & 0 & 0 & 0 \\
MB2 & 2 & 0 & 0 & 0 & 0 \\
\hline
\end{tabular}

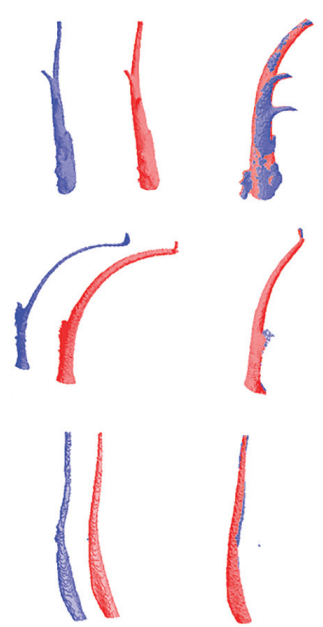

Fig. 1: Three-dimensional reconstructions of micro-CT images showing the root canal space in different roots; (1) representing the palatal canal; (2) the mesiobuccal one canal; and (3) the DB canal. The blue color represents the original canal before instrumentation and the red color the canal after instrumentation with XP-endo Shaper. Un-instrumented areas shown in blue on the merged images

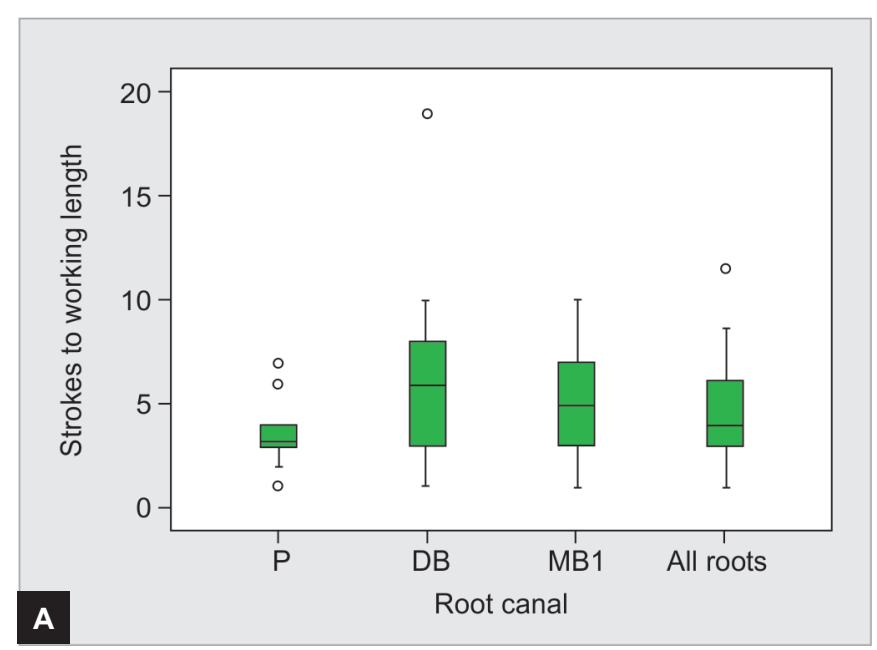

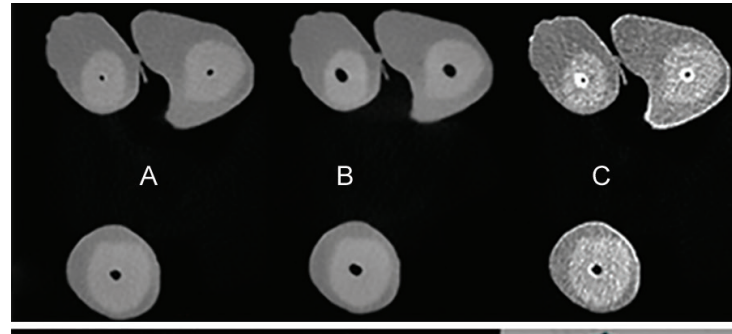

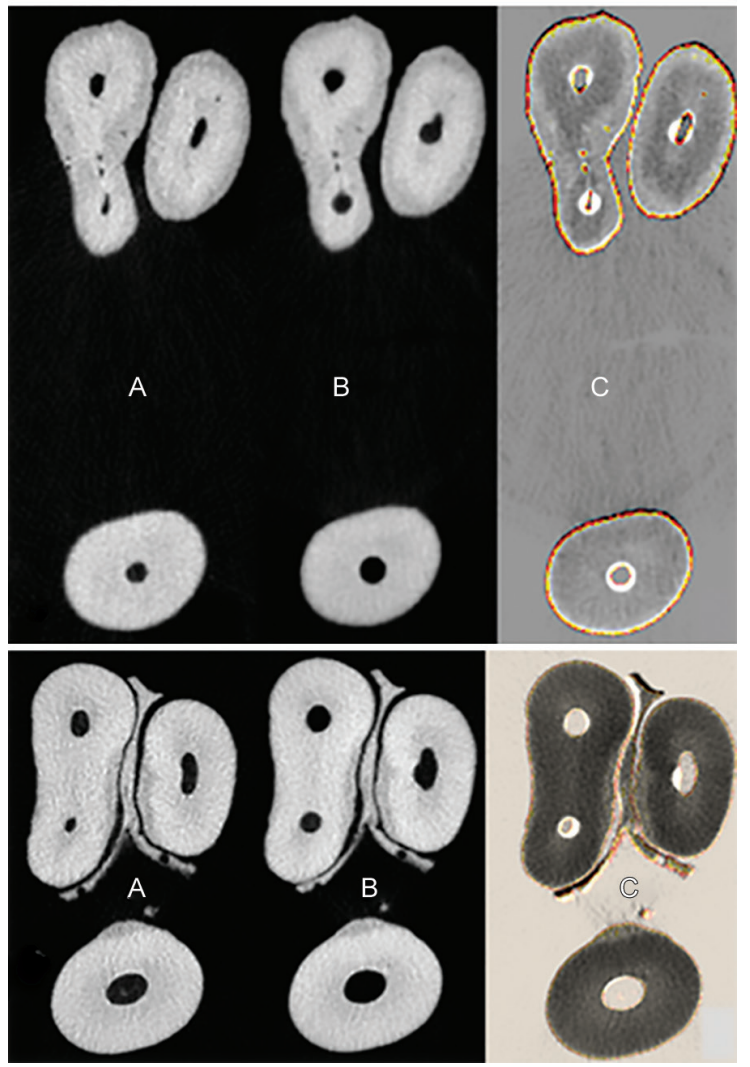

Fig. 2: Cross-sectional illustrations of root canals taken by the micro-CT at different canal levels from different tooth samples, (1) and (2) representing the apical third and (3) the coronal third. (A) pre-instrumentation; (B) post-instrumentation; (C) the merged illustrations in $A$ and $B$. The white shade in $C$ represents the space created by XP-endo Shaper and the gray color represents the original canal space

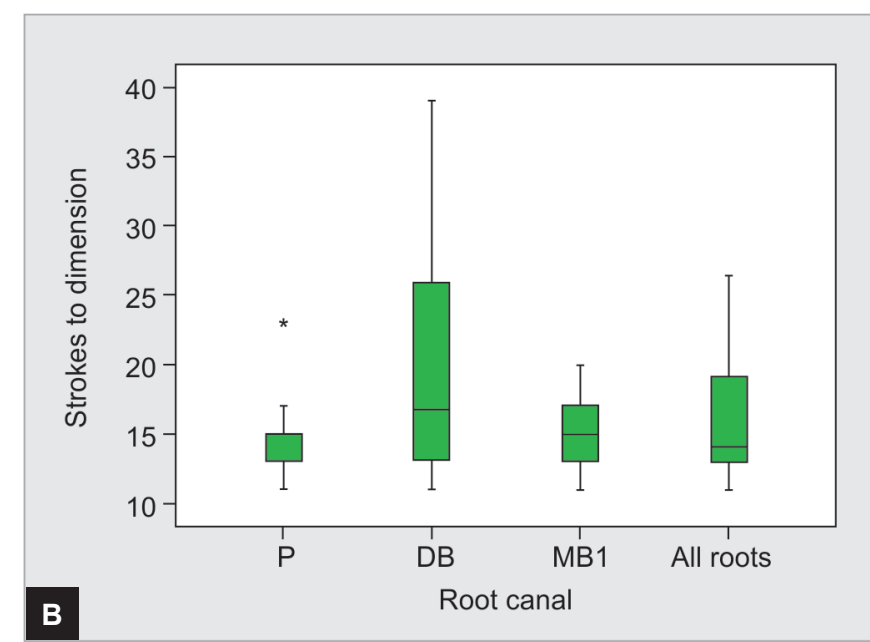

Graphs 2A and B: Variation in strokes for the different root canals. (A) Total number of strokes needed to achieve working length in the different root canals; (B) Total number of strokes needed to achieve final apical dimension in the different root canals. The box-plots to the right represent the total number of strokes needed, irrespective of canal type (all canals pooled). P, palatal; DB, distobuccal; $\mathrm{MB}$, mesiobuccal canal 


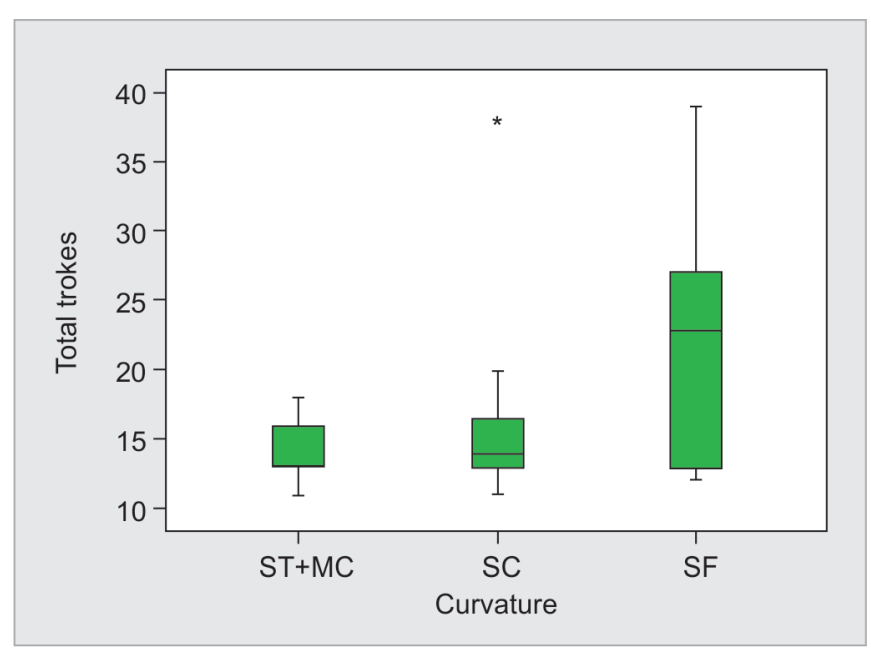

Graph 3: The effect of canal curvature on the number of strokes needed to achieve final canal dimensions. ST+MC, straight + moderate curvature; SC, severe curvature; SF, S-form

divided into separate groups. Canals with SF curvature were three times more frequent in the DB canals compared with the MB and P canals. As illustrated in Graph 3, the results showed no significant differences in total strokes needed between the curvature groups, although the SF curvatures needed the highest number of strokes (median 23 strokes), followed by the SC (median 14 strokes) and the ST+MC canals (median 13 strokes).

The effect of curvature on dentine removal of XP-endo Shaper in the apical $4 \mathrm{~mm}$.

The effect of root canal curvature on the volume increase in the apical $4 \mathrm{~mm}$ after instrumentation with XP-endo Shaper was tested, as a large increase in volume may indicate deviation from the original root canal. All instrumented canals were included. ST and MC curvatures were pooled in one group for statistical purposes, whereas SC and SF canals were in separate groups. The results are presented in Graph 4. No difference in volume change in the apical $4 \mathrm{~mm}$ between the curvature groups was noted.

\section{DISCUSSION}

With the progression of technology, especially after the introduction of computed tomography in endodontics, the advancement in root canal treatment has been enhanced with the intention to achieve a better three-dimensional cleaning, shaping and obturation. Thus, the evolution of new three-dimensional file concepts has resulted in new instruments appearing on the market, especially the nickel-titanium instruments that can expand in the canal to adapt to the canal's natural morphology. Up to present time, there are only three instruments that fall into this category: the self-adjusting file (SAF), XP-endo Shaper and XP-endo finisher. The TRUEShape file system

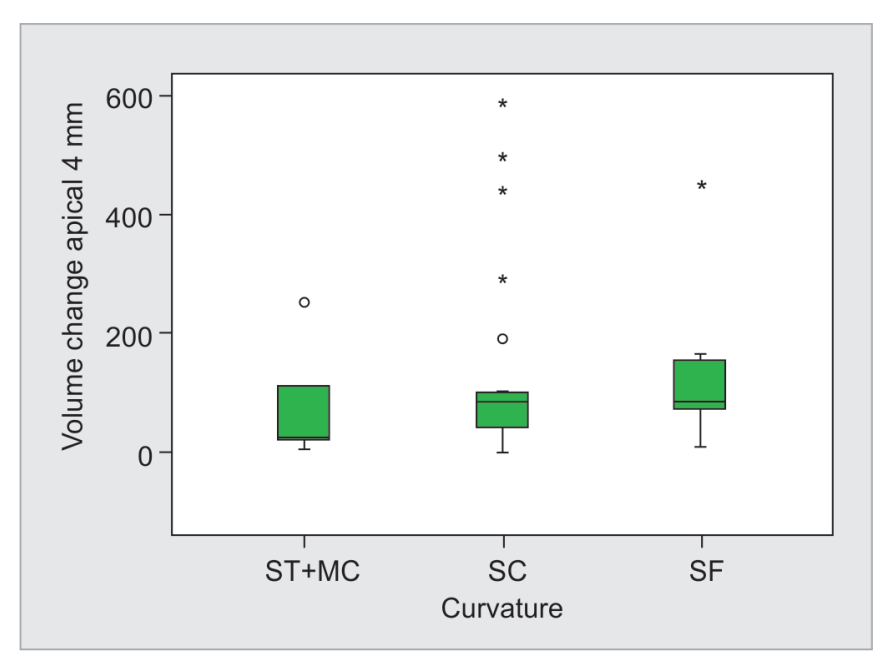

Graph 4: The effect of curvature on the volume change in the apical $4 \mathrm{~mm}$. ST+MC, straight + moderate curvature; SC, severe curvature; SF, S-form

cannot be fully included in this category. It is more like an eccentric NiTi file that can cut slightly outside its central axis of rotation, like for example, Pro-Taper Next and Endosequence. $^{43}$

The SAF system uses a hollow Nickel-Titanium lattice-like cylinder that scrubs the canal wall by vertical vibrations, adapting the file to the root canal rather than shaping the canal like the rotary or hand instruments. ${ }^{36}$ The XP-endo Shaper and finisher are considered to possess an adaptive core, where the extent of motion is greater than the file diameter itself. The XP-endo Shaper was introduced in 2016 and limited data on shaping ability in different root canal configurations are available in the endodontic literature. The aim of the study was to evaluate clinical performance, using the XP-endo Shaper file in 20 maxillary molars with variations in canal morphology. XP-endo Shaper is made of a MaxWire alloy that allows the martensitic instrument to transform to a predetermined austenitic shape at body temperature. ${ }^{44}$ This means that the file will expand from a 0.01 taper (martensitic M-phase at $20^{\circ} \mathrm{C}$ ) to a maximum of 0.08 taper (predetermined austenitic A-phase at $34^{\circ} \mathrm{C}$ ).

The shaping protocol recommendation is to start using the XP-endo Shaper in the largest canal. ${ }^{45}$ In the maxillary molars used, the sequence of canal instrumentation started with the P (largest) canal, followed by DB, MB1, and MB2 canals. The volume of the preparation increased after instrumentation in all canals and at all levels, both at full length and in the apical $4 \mathrm{~mm}$. The volume change was largest in the DB canals, followed by the MB1 and P canals, meaning that the file worked less in the P canals. Taking this into consideration, the recommendation of the manufacturer is relevant and the file should be used first in the largest canal. Using the file in a narrow canal will probably reduce the capacity of the file to expand to 
its maximum taper when used in a wider canal. The two MB2 canals studied separately, showed the largest increase in volume at total length, one with an increase of $1248.13 \%$ and the other $261.09 \%$. The 30/0.04 GP was perfectly fitted in both canals. This confirms that the file has the capacity to expand to at least 30/0.04 taper even in narrow canals.

After the cleaning and shaping procedure, the GP cones that fitted with a tug-back sensation into the final preparation was chosen. The volume of the final canal preparation in the last $4 \mathrm{~mm}$ as compared with the volume of a virtual GP cone fitted in the last $4 \mathrm{~mm}$. The difference in volume indirectly suggests the sealer quantity needed to seal the apical $4 \mathrm{~mm}$. The virtual volume of the gutta-percha cone was determined using the formula of a frustum of a right circular cone. Ideally, the virtual volume of the gutta-percha cone used in the calculations should be equivalent to the cone fitted in the root canal. However, in some cases, a negative value of up to more than $25 \%$ in some of the root canals were found. This finding indicates that there is a relatively great variation in the volume during the manufacturing process of the gutta-percha cones, as shown in previous studies. ${ }^{46,47} \mathrm{An}$ other explanation is that the gutta-percha to some extent may adapt itself to the shape of the canal due to plasticity. This may also indicate that the calculated remaining volumes found are actually larger than estimated.

The number of strokes needed to reach the WL and the final apical dimension was in accordance with the manufacturer's recommendations in most cases. For most of the canals, 5 strokes were needed to reach the WL and additional 10 strokes to finish the canal instrumentation to a minimum of 30/0.04, although variations were noted for different canal configurations. For the SF (S-shaped) canals the number of strokes needed to achieve a 30/0.04 dimension was almost doubled. In two DB canals, presenting SF curvatures, 38 and 39 strokes were used respectively. For the two MB2 canals, 12 and 9 strokes were needed to reach working length, whereas 22 and 19 strokes were used to achieve final shaping of the canals.

No difference in volume change in the apical $4 \mathrm{~mm}$ between the curvature groups was noted. This suggests that the XP-endo Shaper file is not significantly affected by curvature, indicating that the file maintained the original root canal pathway in the apical $4 \mathrm{~mm}$.

From a visual micro-CT observation, it is important to point out that the XP-endo Shaper was active around all the root canal surfaces in the coronal third without altering the original canal shape, especially in the widest canals in the palatal roots. On the contrary, there was an obvious visual change of the original root canal shape into a more circular geometry within the $\mathrm{DB}, \mathrm{MB} 1$ and $\mathrm{MB} 2$ roots. It appears that the initial geometry of the root canal was altered into a more conical shape, in agreement with Versiani et al. ${ }^{48}$

Also for the XP-endo Shaper, un-instrumented areas were observed. Up to date, there is no hand or rotary file that can completely clean and instrument the whole root canal system. In a study, comparing the effect of SAF, TRUEShape and XP-endo Shaper in the apical 4 $\mathrm{mm}$, the SAF exhibited significantly less unprepared areas than the XP-endo Shaper and the TRUEShape file. None of them prepared $100 \%$ of the root canal walls, and the cleaning ability of the three systems was similar. ${ }^{36}$ When the XP-endo Shaper was compared with the Vortex Blue file system in mandibular central incisors, with a single oval canal, there was a tendency toward less debris accumulation in the XP-endo Shaper group, with close to significant results. The XP-endo Shaper removed more dentin than Vortex Blue in the middle and coronal areas, but not in the apical area. ${ }^{40}$ Another study, comparing the shaping ability of BioRace, Reciproc, SAF and the TRUShape system, found the same level of accumulated hard-tissue debris. BioRace was associated with more untouched canal walls, and Reciproc had least dentine saving abilities. The SAF system touched more of the root canal walls and removed less dentine. TRUShape had intermediate results for the same parameters. None of the systems tested provided optimal shaping ability in oval-shaped canals. ${ }^{34}$

A limitation of the study is the transformation of the results into a clinical setting since factors connected to the elimination of infection is not considered. As an endodontic file purely works mechanically, additional measures are required for better cleaning and disinfection of the root canal. Ultrasonic or sonic activation of the disinfectants, EndoVac system, XP-Endo Finisher, and lasers are shown to improve the cleaning and shaping protocol, ${ }^{49-53}$ but long-term treatment outcomes need to be presented. A combination of a microcomputed tomographic and histologic evaluation of extracted teeth could be used to evaluate a possible correlation between un-instrumented root canal areas and accumulation of debris. The un-instrumented areas may thus be of minor clinical importance if the necrotic tissue and debris are eliminated from the root canal during the chemomechanical instrumentation procedure.

\section{CONCLUSION}

Within the limitation of the study, the clinician should be aware of root canal anatomy and complexity in the morphology of the maxillary molars. The XP-endo Shaper showed a good dentine removal ability and cutting efficiency in different canal types and shapes in maxillary 
molars and was able to achieve a root canal preparation of at least size 30 and a 0.04 taper.

\section{CLINICAL SIGNIFICANCE}

The number of strokes needed to obtain the minimum apical dimension of 30/0.04 varied based on root canal configuration, mainly influenced by the canal curvature (S-shaped canals) and the initial volume of the canals (narrow versus wide canals). The severity of the root canal curvature did not influence the relative amount of dentin removed in the apical $4 \mathrm{~mm}$.

\section{ACKNOWLEDGMENT}

Authors would like to acknowledge Stein Atle Lie for statistic advice.

\section{REFERENCES}

1. Averbach RE, Kleier DJ. Clinical update on root canal disinfection. Compend Contin Educ Dent 2006 May;27(5):284-289.

2. Schafer E, Schlingemann R. Efficiency of rotary nickeltitanium K3 instruments compared with stainless steel hand K-Flexofile. Part 2. Cleaning effectiveness and shaping ability in severely curved root canals of extracted teeth. Int Endod J 2003 Mar;36(3):208-217.

3. Schilder H. Cleaning and shaping the root canal. Dental Clin North Am 1974 Apr;18(2):269-296.

4. Hülsmann M, Peters OA, Dummer PMH. Mechanical preparation of root canals: shaping goals, techniques and means. Endod Topics 2005 Mar;10(1):30-76.

5. Usman N, Baumgartner JC, Marshall JG. Influence of instrument size on root canal debridement. J Endod 2004 Feb;30(2):110-112.

6. Paqué F, Ganahl D, Peters OA. Effects of root canal preparation on apical geometry assessed by micro-computed tomography. J Endod 2009 Jul;35(7):1056-1059.

7. Fornari VJ, Silva-Sousa YT, Vanni JR, Pécora JD, Versiani MA, Sousa-Neto MD. Histological evaluation of the effectiveness of increased apical enlargement for cleaning the apical third of curved canals. Int Endod J 2010 Nov;43(11):988-994.

8. Ahlquist M, Henningsson O, Hultenby K, Ohlin J. The effectiveness of manual and rotary techniques in the cleaning of root canals: a scanning electron microscopy study. Int Endod J 2001 Oct;34(7):533-537.

9. Foschi F, Nucci C, Montebugnoli L, Marchionni S, Breschi L, Malagnino VA, Prati C. SEM evaluation of canal wall dentine following use of Mtwo and ProTaper NiTi rotary instruments. Int Endod J 2004 Dec;37(12):832-839.

10. Gambarini G, Laszkiewicz J. A scanning electron microscopic study of debris and smear layer remaining following use of GT rotary instruments. Int Endod J 2002 May;35(5): 422-427.

11. Hülsmann M, Rummelin C, Schäfers F. Root canal cleanliness after preparation with different endodontic handpieces and hand instruments: a comparative SEM investigation. J Endod 1997 May;23(5):301-306.
12. Hülsmann M, Gressmann G, Schäfers F. A comparative study of root canal preparation using FlexMaster and HERO 642 rotary Ni-Ti instruments. Int Endod J 2003 May;36(5):358-566.

13. Paqué F, Musch U, Hülsmann M. Comparison of root canal preparation using RaCe and ProTaper rotary Ni-Ti instruments. Int Endod J 2005 Jan;38(1):8-16.

14. Schäfer E, Vlassis M. Comparative investigation of two rotary nickel-titanium instruments: ProTaper versus RaCe. Part 2. Cleaning effectiveness and shaping ability in severely curved root canals of extracted teeth. Int Endod J 2004 Apr;37(4): 239-248.

15. Wu MK, Wesselink PR. Efficacy of three techniques in cleaning the apical portion of curved root canals. Oral Surg, Oral Med, Oral Pathol, Oral Radiol, Endod 1995 Apr;79(4): 492-496.

16. Siqueira JF, Jr., Alves FR, Versiani MA, et al. Correlative bacteriologic and micro-computed tomographic analysis of mandibular molar mesial canals prepared by self-adjusting file, reciproc, and twisted file systems. J Endod 2013 Aug; 39(8):1044-1050.

17. Peters OA, Arias A, Paqué F. A micro-computed tomographic assessment of root canal preparation with a novel instrument, TRUShape, in mesial roots of mandibular molars. J Endod 2015 Sep;41(9):1545-1550.

18. Paqué F, Zehnder M, De-Deus G. Microtomography-based comparison of reciprocating single-file F2 ProTaper technique versus rotary full sequence. J Endod 2011 Oct;37(10): 1394-1397.

19. Markvart M, Darvann TA, Larsen P, Dalstra M, Kreiborg S, Bjørndal L. Micro-CT analyses of apical enlargement and molar root canal complexity. Int Endod J 2012 Mar;45(3):273281.

20. Zhao D, Shen Y, Peng B, Haapasalo M. Root canal preparation of mandibular molars with 3 nickel-titanium rotary instruments: a micro-computed tomographic study. J Endod 2014 Nov;40(11):1860-1864.

21. Seltzer S, Bender IB, Smith J, Freedman I, Nazimov H. Endodontic failures--an analysis based on clinical, roentgenographic, and histologic findings. II. Oral Surg, Oral Med, Oral Pathol 1967 Apr;23(4):517-530.

22. Seltzer S, Bender IB, Smith J, Freedman I, Nazimov H. Endodontic failures--an analysis based on clinical, roentgenographic, and histologic findings. I. Oral Surg, Oral Med, Oral Pathol 1967 Apr;23(4):500-516.

23. Engström B, Lundberg M. The correlation between positive culture and the prognosis of root canal therapy after pulpectomy. Odontol Revy 1965;16(3):193-203.

24. Iqbal A. The factors responsible for endodontic treatment failure in the permanent dentitions of the patients reported to the college of dentistry, the university of Aljouf, Kingdom of Saudi Arabia. J Clin Diagn Res 2016 May;10(5):146-148.

25. Peters OA, Peters CI, Schönenberger K, Barbakow F. ProTaper rotary root canal preparation: effects of canal anatomy on final shape analysed by micro CT. Int End J 2003 Feb;36(2):86-92.

26. Peters OA, Paqué F. Root canal preparation of maxillary molars with the self-adjusting file: a micro-computed tomography study. J Endod 2011 Jan;37(1):53-57.

27. Hübscher W, Barbakow F, Peters OA. Root-canal preparation with FlexMaster: canal shapes analysed by micro-computed tomography. Int Endod J 2003 Nov;36(11):740-747. 
28. Solomonov M, Paqué F, Fan B, Eilat Y, Berman LH. The challenge of C-shaped canal systems: a comparative study of the self-adjusting file and ProTaper. J Endod 2012 Feb;38(2):209-214.

29. De-Deus G, Souza EM, Barino B, Maia J, Zamolyi RQ, Reis C, Kfir A. The self-adjusting file optimizes debridement quality in oval-shaped root canals. J Endod 2011 May;37(5): 701-705.

30. Shah DY, Wadekar SI, Dadpe AM, Jadhav GR, Choudhary LJ, Kalra DD. Canal transportation and centering ability of protaper and self-adjusting file system in long oval canals: An ex-vivo cone-beam computed tomography analysis. J Conserv Dent 2017 Mar-Apr;20(2):105-109.

31. Jain N, Pawar AM, Ukey PD, Jain PK, Thakur B, Gaupta A. Preservation of root canal anatomy using self-adjusting file instrumentation with glide path prepared by 20/0.02 hand files versus 20/0.04 rotary files. J Conserv Dent 2017 MarApr;20(2):81-85.

32. Bortoluzzi EA, Carlon D, Jr., Meghil MM, El-Awady AR, Niu L, Bergeron BE, Susin L, Cutler CW, Pashley DH, Tay FR. Efficacy of 3D conforming nickel titanium rotary instruments in eliminating canal wall bacteria from oval-shaped root canals. J Dent 2015 May;43(5):597-604.

33. Arias A, Paqué F, Shyn S, Murphy S, Peters OA. Effect of canal preparation with TRUShape and Vortex rotary instruments on three-dimensional geometry of oval root canals. Aust Endod J 2018 Apr;44(1):32-39.

34. Zuolo ML, Zaia AA, Belladonna FG, Silva EJNL, Souza EM, Versiani MA, Lopes RT, De-Deus G. Micro-CT assessment of the shaping ability of four root canal instrumentation systems in oval-shaped canals. Int Endod J 2018 May;51(5):564-571.

35. Silva E, Vieira VTL, Belladonna FG, Zuolo AS, Antunes HDS, Cavalcante DM, Elias CN, De-Deus G. Cyclic and Torsional Fatigue Resistance of XP-endo Shaper and TRUShape Instruments. J Endod 2018 Jan;44(1):168-172.

36. Lacerda M, Marceliano-Alves MF, Perez AR, Provenzano JC Neves MAS, Pires FR, Gonçalves LS, Rôças IN, Siqueira JF Jr. Cleaning and shaping oval canals with 3 instrumentation systems: A correlative micro-computed tomographic and histologic study. J Endod 2017 Nov;43(11):1878-1884.

37. Elnaghy AM, Elsaka SE. Torsional resistance of XP-endo Shaper at body temperature compared with several nickel-titanium rotary instruments. Int Endod J 2018 May;51(5):572-576.

38. Elnaghy A, Elsaka S. Cyclic fatigue resistance of XP-endo Shaper compared with different nickel-titanium alloy instruments. Clin Oral Investig 2018 Apr;22(3):1433-1437.

39. Bayram HM, Bayram E, Ocak M, Uygun AD, Celik HH. Effect of ProTaper Gold, Self-Adjusting File, and XP-endo Shaper instruments on dentinal microcrack formation: a microcomputed tomographic study. J Endod 2017 Jul;43(7):1166-1169.

40. Azim AA, Piasecki L, da Silva Neto UX, Cruz ATG, Azim KA.
XP Shaper, A novel adaptive core rotary instrument: microcomputed tomographic analysis of its shaping abilities. J Endod 2017 Sep;43(9):1532-1538.

41. Schneider SW. A comparison of canal preparations in straight and curved root canals. Oral Surg, Oral Med, Oral Pathol 1971 Aug;32(2):271-275.

42. Cunningham CJ, Senia ES. A three-dimensional study of canal curvatures in the mesial roots of mandibular molars. J Endod 1992 Jun;18(6):294-300.

43. Bellucci F, Ambu E. Root canal shaping with latest generation expanding instruments. https://www.zerodonto.com/ en/2017/12/root-canal-shaping-expansion-endoshaperendofinisher/ Accessed October 20th, 2018.

44. Debelian G, Serota K.S, Trope M, Endodontic reboot - Part one. http://www.dentaltown.com/magazine/articles/6517/ endodontic-reboot-part-one Accessed October20th, 2018.

45. FKG Dentaire SA. XP-Endo shaper protocol card. http://www. fkg.ch/sites/default/files/201705_fkg_xp_endo_shaper_protocol_card_v2_xx_en-fr-de_web.pdf Accessed October 20th, 2018

46. Moule AJ, Kellaway R, Clarkson R, Rowell J, Macfarlane R, Lewis D, Cameron T, Atkins D. Variability of master guttapercha cones. Aust Endod J 2002 Apr;28(1):38-43.

47. Cunningham KP, Walker MP, Kulild JC, Lask JT. Variability of the diameter and taper of size \#30,0.04 gutta-percha cones. J Endod 2006 Nov;32(11):1081-1084.

48. Versiani MA, Carvalho KKT, Mazzi-Chaves JF, SousaNeto MD. Micro-computed tomographic evaluation of the shaping ability of XP-endo Shaper, iRaCe, and EdgeFile systems in long oval-shaped canals. J Endod 2018 Mar;44(3): 489-495.

49. De Moor RJ, Meire M, Goharkhay K, Moritz A, Vanobbergen J. Efficacy of ultrasonic versus laser-activated irrigation to remove artificially placed dentin debris plugs. J Endod 2010 Sep;36(9):1580-1583.

50. Arslan H, Capar ID, Saygili G, Gok T, Akcay M. Effect of photon-initiated photoacoustic streaming on removal of apically placed dentinal debris. Int Endod J 2014 Nov;47(11):10721077.

51. Urban K, Donnermeyer D, Schäfer E, Bürklein S. Canal cleanliness using different irrigation activation systems: a SEM evaluation. Clin Oral Investig2017 Dec;21(9):2681-2687.

52. Nielsen BA, Craig Baumgartner J. Comparison of the EndoVac system to needle irrigation of root canals. J Endod 2007 May;33(5):611-615.

53. Elnaghy AM, Mandorah A, Elsaka SE. Effectiveness of XP-endo Finisher, EndoActivator, and file agitation on debris and smear layer removal in curved root canals: a comparative study. Odontology 2017 Apr;105(2):178-183. 